\title{
THE NEUTRALIZATION OF ENCEPHALITIS VIRUS (ST. LOUIS, 1933), BY SERUM ${ }^{1,2}$
}

\author{
By RALPH S. MUCKENFUSS, JOSEPH E. SMADEL AND ELIZABETH MOORE \\ (From the Department of Medicine, Washington University, St. Louis)
}

(Received for publication September 10, 1937)

The virus of St. Louis encephalitis $(1,2,3)$ was found to be inactivated by substances present in convalescent serum by Webster and Fite (2). Experiments designed to determine the prevalence of neutralizing antibodies against this virus were undertaken concurrently in three separate laboratories. The observations of Wooley and Armstrong (4) and Webster, Fite and Clow (5) have been reported. The present paper represents a final report from our laboratory on neutralization tests done on sera from persons in the St. Louis area.

\section{MATERIALS AND METHODS}

\section{Virus}

Four strains of virus, namely, Daily, Barnes, Freeman (1), and Webster Number 3 (5), were employed in the present study, but the Daily and Barnes strains were used most extensively. Virus for protection tests was obtained as follows: six or eight mice were inoculated intracranially under ether anesthesia with $0.025 \mathrm{cc}$. of a $10^{-1}$ suspension of virus-infected mouse brain; five days later, ${ }^{3}$ when in extremis, the animals were sacrificed and their brains were removed aseptically; a portion of each brain was cultured for contaminants, and the remainder was placed in the freezing coils of the refrigerator where it was kept for from two to four days. Two and sometimes three brains were warmed to room temperature at the time of the test, ground aseptically in a mortar without abrasive and made into an emulsion by the addition of $2 \mathrm{cc}$. of Locke's solution for each brain. The resultant supernatant fluid,

1 Assisted by a grant from the Rockefeller Foundation.

2 Read before the American Society for Clinical Investigation, Atlantic City, N. J., May 6th, 1935. Abstracted in J. Clin. Invest., 1935, 14, 699.

3 During the course of the experiments the incubation period became progressively shorter in passage mice until it was reduced to three days about a year after isolation of the virus. after centrifugation at 500 r.p.m. for two minutes, was then diluted for use in the protection test.

\section{Sera}

Sera obtained from 365 individuals in the St. Louis area were tested. The various sources were : 126 patients reported to have had encephalitis during the epidemic of $1933 ; 139$ patients in Barnes Hospital without history of encephalitis or contact with the disease, who were bled 6 to 15 months after the epidemic; 78 persons in contact with encephalitic patients or with infected material ; and a group of 22 young individuals who had had acute encephalitis or meningo-encephalitis one to ten years before the epidemic of 1933. This last group was collected by $\mathrm{Dr}$. Alexis F. Hartmann from patients in the St. Louis Children's Hospital. Neutralization tests were also performed on 10 sera obtained by Dr. Raymond Meyer of Strasbourg from cases recovered from encephalitis. For a comparison of our results with those obtained in other laboratories, 54 sera sent by Armstrong (4) and 15 by Webster (5) were studied.

\section{Protection test}

Pooled infected mouse brain suspension was diluted in multiples of 10 with Locke's solution to concentrations of $10^{-4}, 10^{-5}$ and $10^{-6}$. Of each of these concentrations, $0.3 \mathrm{cc}$. was mixed with $0.6 \mathrm{cc}$. of the undiluted serum to be tested, and the mixture was incubated at $37^{\circ} \mathrm{C}$. for two hours. Of each virus-serum mixture, $0.025 \mathrm{cc}$. was inoculated intracerebrally into four mice. Seven sera were tested in a single experiment. Injections were made in the following order: the three dilutions of virus with a known negative serum, with a known positive serum, dilutions of virus with the four unknown sera and finally with a second known negative serum. The elapsed time from beginning to end of injections was in the neighborhood of 30 minutes. In part 
of the work, virus dilution $10^{-6}$ was omitted and six mice instead of four were inoculated with dilutions $10^{-4}$ and $10^{-5}$.

All sera were tested on at least two occasions. A number were tested with all four strains of virus. Certain of the sharply positive and negative sera were run many times. Known negative human sera were used as controls.

Mice were observed for 10 days after injection when all animals still alive were considered to have received neutralized virus.

\section{Interpretation of protection tests}

Since neutralizing antibodies, when present in human sera, were never in high concentration, the protection tests were necessarily designed to use virus dilutions close to the limit of infectivity. Ordinarily, all mice in a given test inoculated with a $10^{-4}$ dilution of a normal serum-virus mixture died, as did the majority of those receiving the $10^{-5}$ dilution. Because this was not always the case, two negative controls were used in each protection test and a mathematical method of analysis was instituted. Dr. Paul Rider of the Department of Mathematics and Dr. George Williams of the Department of Anatomy of Washington University gave material assistance in the use of statistical methods.

Three different strains of mice (Swiss, Bell and C57) were employed and each was considered separately from a statistical standpoint. Groups of 4 Swiss or Bell mice were injected with each virus-serum mixture whereas the C57 strain was always used in lots of 6 . The probability of survival of any given number of mice in these groups of 4 or 6 animals after injection with a virus-normal serum mixture was calculated in the usual way; that is, by dividing the number of ways in which the event could occur by the number of ways in which a given number of mice could be drawn.

Table I shows the probable survival rate in a group of 4 Bell mice receiving an unneutralized mixture of serum and Daily virus diluted $10^{-4}$. On the basis of this data it was arbitrarily decided that the survival of 3 mice would indicate protective action of a given serum while the survival of 2 mice would represent doubtful protection, and the survival of less than two mice would connote no neutralizing power. This seems satis-
TABLE I

Probability of survival of Bell mice injected with $10^{-1}$ dilution virus-normal serum mixture

Mice inoculated with daily strain of virus . . . . . 252

Mice surviving ....................... 19

\begin{tabular}{c|c|l|l}
\hline \hline Die & Survive & Probability & Interpretation \\
\hline 4 & 0 & 0.729 & Negative \\
3 & 1 & 0.241 & Negative \\
2 & 2 & 0.028 & Doubtful \\
1 & 3 & 0.0027 & Positive \\
0 & 4 & 0.000027 & Positive \\
\hline
\end{tabular}

factorily conservative since the chance of being correct in attributing protection to a given serum that had been used when 3 mice survived would be about 99.7 per cent. Similarly, an interpretation of "doubtful" represents a probability of 97.2 per cent that some protection was due to the serum.

Similar calculations were made for a group of 252 mice of the C57 strain that had only 6 survivors after an injection with a mixture of a $10^{-4}$ dilution of Daily virus and normal serum. This showed that the probability of none of the six mice in a group surviving was 0.824 while the probability that four would die and two survive was 0.006 . It should be kept in mind that results with the Swiss and C57 strains were more regular than with the Bell mice, therefore the criteria for a positive or negative diagnosis which were used for Bell mice would not lead to false positives when applied to the other two strains, but might put a weakly positive result in the negative column.

The statistical studies above provide for interpretation of only the $10^{-4}$ serum-virus dilution in protection tests and makes no provision for cases in which the virus was more concentrated and killed all of the mice receiving normal serumvirus mixture in the $10^{-5}$ dilution. In such cases, the virus was often too potent in $10^{-4}$ dilution to be neutralized by sera containing a fair amount of neutralizing antibodies but was neutralized in the $10^{-5}$ dilution. Calculation of probability of death after injection of the $10^{-5}$ dilution into the least susceptible Bell mice, prepared by the methods used above, indicated that the chance of 3 mice surviving and one dying in a group of 4 was 0.006 .

To summarize, in groups of 4 mice (Bell and Swiss strains) or 6 mice (C57 strain), the sur- 
vival of 3 animals was considered evidence of protection by the serum. The survival of 2 mice was interpreted as doubtful, and when only one mouse lived the serum was regarded as negative for protecting antibodies.

\section{RESULTS}

Neutralization tests on sera from patients diagnosed as having encephalitis during the epidemic of 1933. Sera from 126 patients reported to the Health Department as having encephalitis during the epidemic in St. Louis were tested for neutralizing antibodies. Of these 87 or 69 per cent were found definitely to neutralize the virus. Sera from 28 patients, or 22.2 per cent failed to show antibodies, while in 11 , or 8.7 per cent the results of the tests could not be definitely interpreted (Table II).

TABLE II

Sera tested for neutralizing antibodies against the virus of St. Louis encephalitis

\begin{tabular}{c|r|r|r|r}
\hline \hline Sera & $\begin{array}{c}\text { Num- } \\
\text { ber of } \\
\text { sera }\end{array}$ & $\begin{array}{r}\text { Per- } \\
\text { cent- } \\
\text { age } \\
\text { posi- } \\
\text { tive }\end{array}$ & $\begin{array}{r}\text { Per- } \\
\text { cent- } \\
\text { age } \\
\text { doubt- } \\
\text { ful }\end{array}$ & $\begin{array}{r}\text { Per- } \\
\text { cent- } \\
\text { age } \\
\text { nega- } \\
\text { tive }\end{array}$ \\
\hline $\begin{array}{c}\text { Patients recovered from epidemic } \\
\text { encephalitis................... }\end{array}$ & 126 & 69 & 9 & 22 \\
$\begin{array}{c}\text { Contacts with encephalitis cases.. } \\
\text { Individuals without known case } \\
\text { contact....................... }\end{array}$ & 139 & 27 & 18 & 55 \\
$\begin{array}{c}\text { Patients with encephalitis during } \\
\text { 10 years previous to epidemic... }\end{array}$ & 22 & 18 & 18 & 64 \\
Patients with encephalitis in & 10 & 0 & 0 & 10 \\
Strasbourg, France.............. & 10 & 0 & 55 \\
\hline
\end{tabular}

The hospital records of 70 of the 126 patients were reviewed in the hope of correlating the laboratory results with the clinical findings. The only relationship which appeared was one that involved the spinal fluid cell counts. Fourteen of the 70 patients did not show neutralizing power; these had an average count of 72 cells. Specimens from 5 of the individuals had 6 or less cells per cubic millimeter, while in only one case was the count above 100 cells. In 10 patients who were considered doubtful as regards neutralizing antibodies the average number of cells in the spinal fluid was 107 . In this group only 3 fluids contained 6 cells or less per cu. mm. Half the sera from patients in the doubtful group were positive on the initial test, shortly after withdrawal of blood, but subsequently after storage were questionable or definitely negative. The average spinal fluid count for this latter portion of the doubtful group was 170 cells. Among the group of 46 convalescents whose sera had undoubted protecting action only one patient had less than 6 cells per cu. mm. in the spinal fluid; the average for the group was 144 per cu. $\mathrm{mm}$.

Seventeen patients were bled again for testing, after intervals of 4 to 14 months from the time the initial specimen was obtained. Twelve of these were positive on both occasions and 2 were uniformly negative. In 2 cases sera were positive initially but doubtful 7 and 11 months later, respectively. The questionable protection found with one patient's serum obtained several weeks after the onset of encephalitis was changed to positive protection in a second sample 14 months later.

Neutralization tests on sera from individuals in contact with cases of encephalitis. Sera from 78 individuals who were in contact with cases of encephalitis during the epidemic were studied for neutralizing antibodies against the virus. The results for the entire group were: positive 26.9 per cent, doubtful 17.9 per cent and negative 55.1 per cent (Table II). Among the contacts, 48 were members of patients' families, 19 were physicians and nurses active in caring for hospitalized patients with encephalitis, and 11 were laboratory workers who handled infected material or animals. Positive protection with these three groups was obtained in 33.3 per cent of the home contacts, 15.8 per cent of the hispital contacts and 18.1 per cent of the laboratory contacts.

Neutralization tests on sera from individuals in the St. Louis area without history of direct contact with encephalitis patients. Residents of the St. Louis area who had not had encephalitis and had had no known direct contact with cases of encephalitis were bled from 8 to 15 months after the epidemic, while hospitalized for various diseases. Neutralization experiments done on sera from 139 of these patients gave the following results: positive 35.9 per cent, doubtful 9.37 per cent, and negative 54.7 per cent (Table II).

Neutralization tests on sera of patients with non-epidemic encephalitis. Twenty-two children and young adults who had had encephalitis or meningo-encephalitis during the 10 years prior to the epidemic of 1933 were bled for serum 8 to 10 
months after the epidemic. Of these sera, 18.1 per cent protected against the virus, while 18.1 per cent of the results were of doubtful interpretation and 63.6 per cent of the sera failed to protect. The percentage of negative sera in this group will be seen (Table II) to correspond with that of the contact and non-contact groups.

Sera from 10 cases of encephalitis of different types occurring in Strasbourg, France, were uniformly without protecting antibodies. This would seem to indicate that no etiological relationship exists between the encephalitis of Strasbourg and the present form. Caution is necessary, however, in interpreting these results, since the sera were tested some time after collection and, from our own observations and those of others (5), the neutralizing power of sera diminishes after a few weeks of storage in the cold.

Neutralization tests with different strains of virus. Thirty-one sera were tested with 4 strains of virus both in the same and in different experiments. The results indicated no immunological variation although some difference in infective titer of individual strains was encountered.

Results of sera tested by other laboratories. Sera collected from 54 persons were sent by Armstrong (4). Our tests showed 35.1 per cent to be positive, 11.2 per cent doubtful and 53.7 per cent negative. These sera chosen at random from Wooley and Armstrong's (4) total of 524 represents an adequate sample. The results of these authors for their entire series (38.6 per cent positive, 10.7 per cent questionable and 50.7 per cent negative) agree closely with our findings in the portion that we tested. The results of duplicate tests done on 15 of Webster's (5) sera agreed less completely, for he found 7 of the number positive while in our hands 11 sera neutralized the virus. All the sera that Webster considered positive were likewise positive in our tests but 4 of his negative group contained neutralizing antibodies by our methods.

\section{DISCUSSION}

Sera from 365 inhabitants of the St. Louis area were tested for the presence of neutralizing antibodies against the virus of St. Louis encephalitis. These sera were collected and tested over a period from September, 1933 to June, 1935. Sixty-nine per cent of 126 patients diagnosed as having had epidemic encephalitis possessed such antibodies while 22 per cent did not; tests on the remaining 9 per cent were doubtfully positive. In 71 of 217 individuals ( 32.7 per cent) in the area who had had no clinical evidence of encephalitis, neutralizing antibodies were demonstrated. The percentage of negative sera from persons who had been in contact with patients was about equal to that of individuals who had no history of such contact. No significant variation from the general distribution of neutralizing antibodies was found among 22 children and young adults who had had encephalitis during the 10 years previous to the epidemic.

No attempt was made to discard cases which had been diagnosed epidemic encephalitis on what seemed, when the records were reviewed, to be meager clinical evidence. Five such cases whose sera failed to neutralize the virus were found among 70 records studied; this indicates that approximately 7 per cent of the individuals reported with epidemic encephalitis may have had some other illness. Atypical or incorrectly diagnosed cases probably account for our low percentage of positive sera among convalescents. Wooley and Armstrong (4) found protective antibodies in 94 per cent of 39 patients from St. Louis with clinically definite epidemic encephalitis of 1933, while Webster, Fite and Clow (5) obtained positive results on 82.5 per cent of 29 convalescent sera from St. Louis.

A loose correlation appeared to exist between the severity of the meningeal cellular reaction and the occurrence of protective antibodies in the sera of patients. Convalescents with positive sera had a significantly higher average spinal fluid cell count than did patients with negative sera.

The specificity of the neutralization test for this virus has been adequately demonstrated by Webster et al. (5). Wooley and Armstrong (4) have discussed the epidemiological significance of the frequency with which neutralizing antibodies were encountered among healthy individuals of the epidemic area. Our results have likewise led us to believe that the virus was the cause of widespread subclinical infection in the epidemic area.

Close correspondence between our tests and those of Wooley and Armstrong was found both in the percentage of positive sera among home contact groups and in the duplicate sera tested in 
both laboratories. While our results agree in general with those of Webster there is a marked difference in the St. Louis non-encephalitis sera group. He found no neutralizing power in any of the 8 sera tested. The most likely explanation for this difference is twofold. In the first place, Webster used equal amounts of test serum and virus dilution while in the experiments of Wooley and Armstrong and in our own, two volumes of test sera were incubated with one volume of virus dilution; this latter technique might pick up weakly positive sera which would be missed by another method. Secondly, the method of interpreting Webster's tests " renders it unlikely that a negative serum would be called positive but admits the possibility of a few weakly positive sera being called negative" (5).

Neutralization tests were undertaken on 22 individuals who had been treated for encephalitis or meningo-encephalitis in the St. Louis Children's Hospital during the ten years previous to the epidemic of 1933 . It seemed likely that had the virus under discussion been active during this earlier period many of these children would show neutralizing antibodies. The percentage of positive and negative sera in this group corresponded closely with the percentages in the general population; hence the observations failed to throw light on the question of the previous existence of the virus in the St. Louis area.

\section{SUM MARY}

Sera from 126 of the 1097 patients diagnosed as having encephalitis during the 1933 epidemic in St. Louis were tested for their power to neutralize the virus of St. Louis encephalitis. In 69 per cent, neutralization was demonstrated while 9 per cent were found to be doubtfully positive.

Thirty-three per cent of the sera obtained from 217 individuals of the epidemic area who had no history of encephalitis were also found to neutralize the virus. The group was composed of persons who had direct contact with encephalitis patients and others without known contact; no significant difference was found in the two groups.

\section{BIBLIOGRAPHY}

1. Muckenfuss, R. S., Armstrong, C., and McCordock, H. A., Encephalitis-studies on experimental transmission. Pub. Health Rep., 1933, 48, 1341.

2. Webster, L. T., and Fite, G. L., A virus encountered in the study of material from cases of encephalitis in the St. Louis and Kansas City epidemics of 1933. Science, 1933, 78, 463.

3. Muckenfuss, R. S., Armstrong, C., and Webster, L. T., Etiology of the 1933 epidemic of encephalitis. J. A. M. A., 1934, 103, 731.

4. Wooley, J. G., and Armstrong, C., The distribution of immunity against encephalitis virus of the St. Louis type in the United States as determined by the serum-protection test in white mice. Pub. Health Rep., 1934, 49, 1495.

5. Webster, L. T., Fite, G. L., Clow, A. D., Muench, H., Experimental studies on encephalitis. IV. Specific inactivation of virus by serum from persons exposed to encephalitis, St. Louis type, 1933. J. Exper. Med., 1935, 62, 827.

6. Webster, L. T., and Clow, A. D., The limited neurotropic character of the encephalitis virus (St. Louis type) in susceptible mice. J. Exper. Med., 1936, 63, 433. 